\title{
A Modified ABC-SQP-Based Combined Approach for the Optimization of a Parallel Hybrid Electric Vehicle
}

\author{
S. N. Shivappriya ${ }^{1}$, S. Karthikeyan ${ }^{2}$, S. Prabu ${ }^{3}{ }^{(0)}$, R. Pérez de Prado ${ }^{4, *}$ (D) and \\ B. D. Parameshachari ${ }^{5}$
}

1 Kumaraguru College of Technology, Coimbatore, Tamil Nadu 641049, India; shivapriyakvp@gmail.com

2 M. Kumarasamy College of Engineering, Karur, Tamil Nadu 639113, India; skarthik.me@gmail.com

3 Mahendra Institute of Technology, Namakkal, Tamil Nadu 637503, India; vsprabu4u@gmail.com

4 Telecommunication Engineering Department, University of Jaén, 23700 Jaén, Spain

5 GSSS Institute of Engineering and Technology for Women, Mysuru 570016, India; parameshbkit@gmail.com

* Correspondence: rperez@ujaen.es

Received: 31 July 2020; Accepted: 24 August 2020; Published: 1 September 2020

check for updates

\begin{abstract}
In this paper, an improved fuel consumption and emissions control strategy based on a mathematical and heuristic approach is presented to optimize Parallel Hybrid Electric Vehicles (HEVs). The well-known Sequential Quadratic Programming mathematical method (SQP-Hessian approach) presents some limitations to achieve fuel consumption and emissions control optimization, as it is not able to find the global minimum, and it generally shows efficient results in local exploitation searches. The usage of a combined Modified Artificial Bee Colony algorithm (MABC) with the SQP approach is proposed in this work to obtain better optimal solutions and overcome these limitations. The optimization is performed with boundary conditions, considering that the optimized vehicle performance has to satisfy Partnership for a New Generation of Vehicles (PNGV) constraints. The weighting factor of the vehicle's performance parameters in the objective function is varied, and optimization is carried out for two different driving cycles, namely Federal Test Procedure (FTP) and Economic commission Europe-Extra Urban Driving Cycle (ECE-EUDC), using the MABC and MABC with SQP approaches. The MABC with SQP approach shows better performance in terms of fuel consumption and emissions than the pure heuristic approach for the considered vehicle with similar boundary conditions. Moreover, it does not present significant penalties for final battery charging and it offers an optimized size of the key vehicle's components for different driving cycles.
\end{abstract}

Keywords: automotive system; SQP approach; dynamic optimization; parallel hybrid electric vehicle; artificial bee colony; optimization algorithm

\section{Introduction}

Nowadays, the modern ways are initialized to minimize the impact on natural resources and to increase the dependency over the non-renewable resources, due to the increasing fuel prices and environmental issues [1]. The improvement in the automobile science helps to create the modern ways for minimizing the usage of gasoline [2]. Many years of devoted research has culminated in the improvement of Hybrid Electric Vehicle (HEV) technology. The increase in vehicle numbers subsequently increases the pollution, which causes global warming [3]. In order to save the earth balance, it is mandatory that automotive industries have to produce low-emission and better energy-efficient vehicles. HEV performance with reduced emissions and improved fuel efficiency seems to be promising as one kind of an alternative technology [4]. In hybrid cars, the battery in the vehicle acts as an additional energy source to supplement the main engine, so that the vehicle operates at its maximum possible efficiency [5]. The battery in the vehicle acts as an additional electrical form of energy source to 
supplement the main engine, such that the vehicle operating efficiency is shifted towards its maximum possible efficiency and the vehicle operation range is extended. Also, the control strategy [6] for the vehicle has to be properly adapted. The emission reduction and increment in fuel economy are the most difficult goals in the automotive industry. The cooperative agreements, legislative efforts and society causes the major constraints in the automotive industry. The aforementioned requirements are solved by using the capacity of the HEV as well as these HEV are considered as alternative for the conventional vehicles. Hence, the minimum fuel optimal control issue is solved by using the novel control strategy in parallel HEV. The major contributions of this research are indicated as follows. This paper studies the optimization of parameters of an electric assist control strategy for a parallel HEV. From this study, a Sequential Quadratic Programming (SQP) mathematical method for a parallel HEV has been developed with a Modified Artificial Bee Colony algorithm (MABC) to minimize the instantaneous fuel consumption of the vehicle. The developed control method mainly concentrates on the fuel consumption minimization along with the improvement in power demand and drivability. Furthermore, the hybrid combination of MABC with SQP is used to optimize the size of the components. Results show that the MABC with SQP approach shows better performance in terms of fuel consumption and emission than the pure heuristic approach for the considered vehicle with similar boundary conditions.

This research paper can be summarized as follows. It presents a literature review of recent techniques for optimization of HEV in Section 2, the proposed method with control parameters configurations is described in Section 3, simulation results are provided in Section 4, and the main conclusions of the research are drawn in Section 5.

\section{Literature Review}

In the literature, several associated works are available which are based on optimization of HEVs. Certain critical works are assessed here to justify the contribution of this work.

Enang et al. [7] presents comprehensive, quasi-static longitudinal modeling and parallel HEV validation. Further research was carried out over the New European Driving Cycle (NEDC) using the validated model for investigating the impact of an early gear upshift on cumulative fuel consumption. In this work, without any change in the final battery charging state, better real-time fuel saving is achieved. In spite of the fuel saving potential of this control strategy, the technique employed is unable to guarantee cost function (fuel consumption) optimality. It also cannot satisfy itself in real time, in the end.

Zhang et al. [1] have thoroughly analyzed the various HEV energy management strategies based on bibliometric and propose that driving cycle recognition would help with better energy management of HEVs. For most common types of energy management strategies, which are used in depth in HEVs, the statistical analysis is carried out, with essential characteristics containing pros and cons. Interconnections and scope for change between the different energy management strategies are also exposed from the control point of view. But, this study has not given any basic design as an illustration and relevance for an optimized vehicle design and output for different energy management strategies. Similarly, Shankar has analyzed the design of parallel hybrid electric vehicles for Indian road conditions [8].

Long, and Nhan [9] used the Pheromone-Based Bees Algorithm (PBA) to optimize the size of key component and controlling strategy of parallel HEV. The developed PBA modifies the parameters of control strategy and size of key component for minimizing the emission and Fuel Consumption (FC), while vehicle efficiency meets PNGV constraints. In this analysis, MATLAB software has been employed as a simulation tool, and driving cycles Federal Test Procedure (FTP) and European Driving Cycle (ECE-EUDC) are utilized to evaluate FC, emissions, and dynamic performances [10]. However, in this paper, the effect and change in weightage of objective function parameters and its effect on vehicle design and change in its performance are not discussed [11]. 
Namwook described the global optimality of HEV fuel optimization from a mathematical point of view [12]. This work analyzes the optimality of the Equivalent Consumption Minimization Strategy (ECMS) and the optimal-control-theoretical Pontryagins Minimum Principle (PMP) concept. The control algorithm used in the fuel economy of the hybrid vehicle is found to be very similar in a static simulation for a power-split hybrid vehicle, usually within $1 \%$ of the fuel economy through global optimal control based on Dynamic Programming (DP). But, the emission levels of the vehicle are not taken into account and are not compared against any global standards to prove that the optimized vehicle, after adopting PMP, is within the practical required limits.

Although these algorithms tend to obtain the minimum solution in a reduced time, the solutions generally tend to be local optimum solutions rather than reaching the global optimum for most generic problems. Also, there were some optimization approaches proposed earlier, which mainly concentrate on reducing the fuel emissions, whereas the exhaust gas emissions were not controlled. Wu presents a parallel HEV optimization methodology with Particle Swarm Optimization (PSO) for enhancing vehicle performance [13]. Neubauer has presented a paper which concentrates on vehicle efficiency variation through deriving an adapted driving cycle based on driver aggression [14,15].

Montazeri-Gh and Poursamad [16] concentrated on the methodological technique for optimizing the sizing and control technique parameters of HEV components. In this study, a Genetic Algorithm (GA)-based multi-objective optimization problem is formulated. The FC's weighted sum and three main emissions are reduced by using the objective function. The PNGV performance criteria are used as constraints. Optimization takes place with three different driving cycles. The result shows that, with less simulation time, better objective values are achieved compared with the traditional approach. However, the current GA's for the multi-parameter optimization are generally found to be slow at converging, and hence it is possible to get entrapped into local optimal solutions.

A performance comparison is made between PSO- and Advanced Vehicle Simulator (ADVISOR) [17] based approaches, and the results show that PSO gives preferable parameters effectively without sacrificing dynamic performance of the vehicle [18]. However, it is also described that the PSO is leaning toward premature and fast convergence in sub-optimal points, as well as sluggish convergence in a narrowed search area [13]. Zhang has developed an adaptive energy management strategy based on the identification of driver trends [1].

Long [19] focuses on improving fuel economy only. However, in the engine operation map, the fuel-efficient operating points and emission-efficient operating points lie in different parts. They have shown the improvement in fuel economy but have not discussed about the corresponding change in emission.

A significant similarity of the above studies is that the optimal design approach is either for the component sizing or the HEV control strategy, with other parameters being kept unchanged. Additionally, even if both cases are considered, the evaluation is not shown for different driving cycles with modified weighting factors to emission and fuel consumption parameters in the objective function. Also, either a heuristic or a mathematical approach is used.

Also, a work published by Gowrishankar [20] shows that the MABC approach is better than the Basic Artificial Bee Colony (BABC) approach, in which only the heuristic approaches are compared and there is no comparison provided against any other approaches for the vehicle optimization [20].

However, practically in a vehicle, both the component size and the control strategy influence each other in achieving the vehicle performances. Hence, it becomes imperative to simultaneously optimize component sizes and control strategy parameters. Thus, the key challenge here is to study the effects of change in the weighting factor of fuel usage and emission parameters in objective function. This would help to understand their effects on component size, for different driving cycles, in order to reach a better optimal design for a vehicle, along with adaptation of a proper control strategy. The results show that the proposed MABC with SQP-Hessian approach is a stronger algorithm compared to the pure heuristic MABC approach in achieving better optimization results, with the similar boundary conditions, while still satisfying the PNGV constraints like acceleration and vehicle grade requirements. 


\section{Parallel HEV Configuration and Control Parameter Optimization Targets}

In this paper, a parallel hybrid electric vehicle is considered for optimization. In parallel HEV, the wheels can be driven directly, either electrically or by engine. In some driving modes, both of them could even be used simultaneously [11]. This is one of the most common types of hybrid electric vehicle used in the market due to its unique advantages like higher efficiency for long driving and higher flexibility in switching among Internal Combustion Engine (ICE) and electric motor. The block diagram for a parallel HEV is shown below in Figure 1.

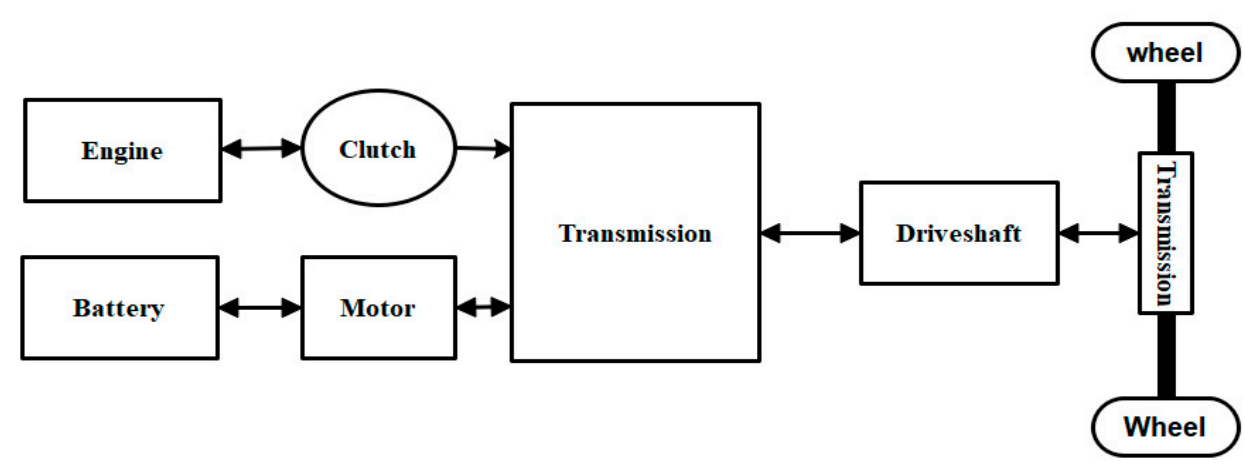

Figure 1. Parallel hybrid electric vehicle (HEV) block diagram.

The key components of the vehicle size, which would be considered for optimization, would be internal combustion engine, electric motor, and battery. The key objective function of this research is to minimize the Fuel Consumption ( $F C$ ), Carbon Monoxide (CO), Nitrous Oxide (NOX), and Hydrocarbons $(H C)$, so as to obtain maximum vehicle performance, subject to Partnership for a New Generation of Vehicles (PNGV) constraint limits. The objective function is as follows in Equation (1):

$$
\operatorname{Min} F(y)=d_{1} F C+d_{2} C O+d_{3} N O X+d_{1} H C
$$

$y \in Y$, where ' $Y$ ' is the feasible solution search space. ' $y$ ' is a variable vector that contains a vehicle component size and parameters of control strategy, and ' $d_{1}$ ' to ' $d_{4}$ ' are termed as weighting factors of different parameters considered in the objective function, which can vary between 0 and 1 , indicating degree of weightage of the parameter optimized and to investigate the effect of different parameters on the optimization results. Subjected to $v(y)>0$ for $y=1$ to 8 , the PNGV constraint limits as defined by the US Consortium are as stated below in Equations (2)-(9):

$$
\begin{aligned}
& \text { Acceleration time is } \leq 12 \mathrm{~s} \text { for } 0-60 \mathrm{mph} \\
& \text { Acceleration time is } \leq 5.3 \mathrm{~s} \text { for } 40-60 \mathrm{mph} \\
& \text { Acceleration time is } \leq 23.4 \mathrm{~s} \text { for } 0-85 \mathrm{mph} \\
& \text { Gradeability is } \geq 6.5 \% \text { at } 55 \mathrm{mph} \text { for } 1200 \mathrm{~s} \\
& \text { Maximum speed is } \geq 85.1 \mathrm{mph} \\
& \text { Maximum acceleration is }>16.4 \mathrm{ft} / \mathrm{s}^{2} \\
& \text { Distance is }>140 \mathrm{ft} \text { in } 5 \mathrm{~s} \\
& \text { Delta State of Charge }(\triangle \mathrm{SOC}) \text { is } \leq 0.5 \%
\end{aligned}
$$

Also, subjected to the following operating conditions:

a. Engine power is

$$
\text { Peng }>0
$$


b. The power output of the engine is restricted to the max power rating of the engine

$$
\text { Peng }<\text { Peng_max_power }
$$

c. For the charge-sustaining control system response, the State of Charge (SOC) of the battery should be always within:

$$
\text { SOClow }<\text { SOCbattery }<\text { SOChigh, }
$$

the defined minimum and maximum limits.

In this work, an analysis has been performed on HEV with two different driving cycles, by varying the values of weighting factors in Equation (1), to analyze their effect on vehicle performances. The control strategy is considered as an important role on the performance and fuel economy of a vehicle. This research paper uses the Electric Assist Control Strategy (EACS). This is a type of charge-sustaining strategy, which means that the battery charge is always maintained between low and high State of Charge (SOC) levels [4]. The primary energy source is the ICE in this technique and the secondary source is electric motor. EACS uses the electric motor at low speeds, where either the ICE does not operate efficiently or where the power required goes beyond the maximum deliverable torque of the engine. If the State of Charge (SOC) of battery is low, the engine supports the battery charging through the electric motor.

\subsection{Driving Cycles}

The FTP and ECE-EUDC transient cycles are considered as the base driving cycles for the analysis. These vehicle driving cycles are considered due to the fact that the vehicle under study is a light-duty passenger car and they cover the majority part of the different driving conditions that a vehicle would face during its usage [21]. The corresponding driving cycle details are as shown in Figures 2 and 3.

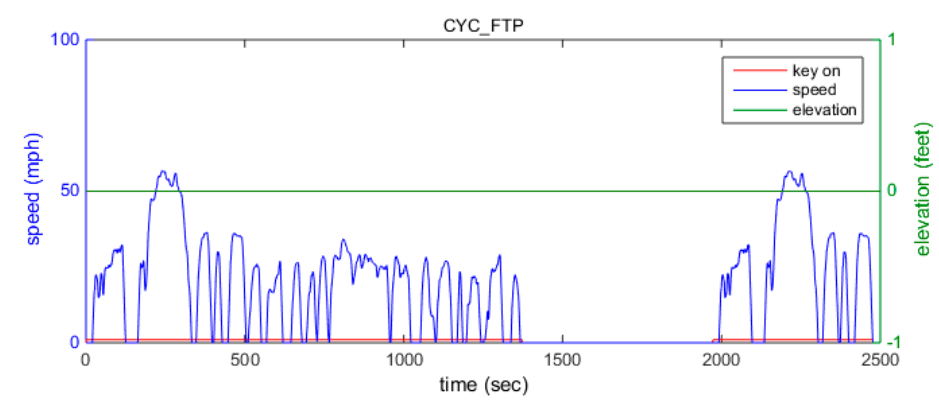

Figure 2. Federal Test Procedure (FTP) driving cycle.

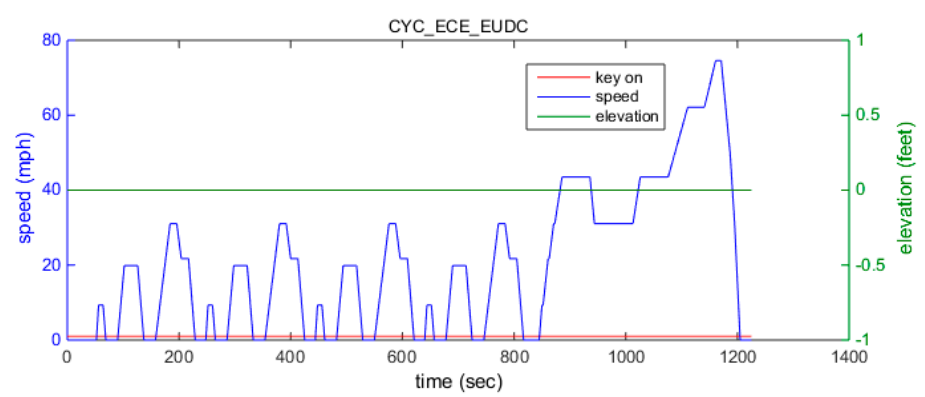

Figure 3. Economic commission Europe-Extra Urban Driving Cycle (ECE-EUDC) driving cycle.

The ECE-EUDC (also called NEDC) driving cycle has four repeating ECE segments without interruption, followed by a single EUDC segment. The Federal Test Procedure (FTP) is similar to the UDDS plus the first $505 \mathrm{~s}$ of an extra UDDS cycle. UDDS stands for Urban Dynamometer Driving 
Schedule, and represents city driving conditions of a passenger car vehicle. It consists of a city route with 17 stops for a distance of 7.5 miles. The average and the maximum speeds are 19.6 miles per hour and 56.7 miles per hour. The idle time and the total cycle time are 259 and $1369 \mathrm{~s}$, respectively.

\subsection{Control Strategy}

To obtain the minimum fuel consumption and emission targets during vehicle optimization [6], the control strategy is used to identify the ideal operating point of the vehicle's engine and motor. The flexibility of this strategy lies in allowing a vehicle to adjust its controls by considering the driving location or limits for local control of vehicle, real-time adjustment to driving cycles, and incorporating the temperature effects on fuel use, engine-out emissions, and catalyst behavior. In this analysis, the parallel EACS has been utilized [22]: the EACS uses the motor for additional power, when needed by the vehicle, and maintains the charge in the batteries. This strategy uses the electric motor in different ways:

1. The motor is utilized in all driving torque, when the vehicle is operated in certain minimum speed.

2. The motor is utilized for torque assist at the operating speed of engine, when the required torque is greater than max torque which is delivered by the engine.

3. Through regenerative braking, the motor charges the batteries.

4. The motor will be used to produce the required torque when the engine runs inefficiently for a required engine torque at the given speed. Also, the engine shuts off at this condition.

5. When there is low-battery SOC condition, the motor will charge the battery through the excess torque provided by the engine.

\subsection{Vehicle Configuration for Optimization}

The vehicle considered for the optimization is a parallel hybrid electric vehicle, with a gasoline engine and battery as sources of power for vehicle driving [2]. The key parameters of the vehicle considered are as depicted in Table 1 . The optimization is performed using the MATLAB simulation tool [23]. In this analysis, the key input parameters considered are fuel converter scaling factor for torque range, motor/controller torque scaling range, number of battery modules, and a set of control strategy parameters, as shown in Table 2 below.

The mentioned parameters are given as input to the MABC and combined MABC-SQP algorithm and the resultant optimized outputs in terms of fuel consumption and emissions are obtained. The approaches are discussed in detail below.

Table 1. Vehicle Parameters.

\begin{tabular}{cc}
\hline Vehicle Parameters & Description \\
\hline Type of the Engine & SI Engine Geo $1.0 \mathrm{~L}(41 \mathrm{~kW})$ \\
Mass (m) of the Vehicle & $592 \mathrm{~kg}$ \\
Power train & Parallel Hybrid \\
Efficiency of the motor & $92 \%$ \\
Motor & $34 \%$ \\
Fuel converter efficiency & AC Induction motor Westinghouse, $75 \mathrm{~kW}$ \\
Transmission & 5 -Speed Manual Transmission \\
Radius of the Wheel, Rw & $0.282 \mathrm{~m}$ \\
Coefficient of drag, Cd & 0.335 \\
Frontal area, Af & $2.0 \mathrm{~m}^{2}$ \\
\hline
\end{tabular}


Table 2. Optimization Parameter definition.

\begin{tabular}{cc}
\hline Parameter & Definition \\
\hline & Input Variables \\
\hline CS_hi_soc & $\begin{array}{c}\text { Highest battery State of Charge (SOC) value desired } \\
\text { Lowest battery State of Charge value desired }\end{array}$ \\
CS_lo_soc & At low SOC, vehicle speed below which vehicle runs as pure electric \\
CS_EL_Speed_lo & At high SOC, vehicle speed below which vehicle runs as pure electric \\
CS_off_trq_frac & Minimum torque threshold at which the engine will SHUT OFF when commanded \\
at lower torque
\end{tabular}

\subsection{Details on SQP-Hessian Approach}

A bisection-based Sequential Quadratic Programming (SQP) method is used to determine the required component sizes, fuel usage, and emission performance based on the performance criteria specified as a part of the analytical approach. For the given minimization problem, an approximation of the Lagrangian function Hessian using a quasi-Newton updating method is made at each big iteration. Given for a general minimization problem description in a general problem, the main idea is to formulate a QP sub-problem based on a quadratic approximation of the Lagrangian function.

$$
\mathrm{L}(\mathrm{x}, \lambda)=f(x)+\sum_{i=1}^{m} \lambda_{i} \cdot g_{i}(x)
$$

where $f(x)$ is the main objective function, $g_{i}(x)$ are the inequality constraints, $\lambda_{i}$ is Lagrange multipliers under the non-negativity constraint, and $\mathrm{m}$ is the total number of restrictions. Implementation of SQP consists of four main stages, as outlined below.

Updating the Hessian Matrix. The definite positive quasi-Newton approximation of the Lagrangian Hessian equation, $H$, is calculated in each major iteration, where $\lambda_{i}, i=1, \ldots, m$, is an estimate of the Lagrange multipliers.

$$
H_{k+1}=H_{k}+\frac{q_{k *} q_{k}^{T}}{q_{k}^{T} * s_{k}}-\frac{H_{k * s_{k} * s_{k}^{T} * H_{k}^{T}}}{s_{k}^{T} * H_{k} * s_{k}}
$$

where

$$
\begin{gathered}
s k=x k_{+1}-x k \\
q_{k}=\left(\nabla f\left(x_{k+1}\right)+\sum_{i=1_{i}}^{m} \cdot \nabla g_{i}\left(x_{k+1}\right)\right)+\left(\nabla f\left(x_{k}\right)+\sum_{i=1_{i}}^{m} \cdot \nabla g_{i}\left(x_{k}\right)\right)
\end{gathered}
$$

Quadratic Programming (QP) Solution. The solution for the QP is computed using 2 steps:

1. Generation of feasible points.

2. Detection of the feasible point in which the convergence takes place with number of iterative sequences.

A search path generated by a linear summation of any combination of the Zk columns is guaranteed to remain at the limits of the active constraints. The matrix $\mathrm{Zk}$ is generated from the last $\mathrm{m}-1$ columns 
of the QP decomposition of the matrix of $\overline{A_{k}^{T}}$, where the amount of active constraints is represented as 1 and $\mathrm{l}<\mathrm{m}$. That is, $\mathrm{Zk}$ is given by

$$
\mathrm{Zk}=\mathrm{Q}[:, 1+1: \mathrm{m}]
$$

where

$$
Q T \overline{A_{k}^{T}}=\left[\begin{array}{l}
R \\
0
\end{array}\right]
$$

If $\mathrm{Zk}$ is found, a direction of new search $\hat{d}_{k}$ is sought that minimizes $\mathrm{q}(\mathrm{d})$, where $\hat{d}_{k}$ is in the null space of the active constraints.

Initialization. The algorithm calls for a feasible starting point. If the current point of the SQP approach is not feasible, the Linear Programming (LP) problem can be solved as is shown below:

$\min \gamma$, such that:

$$
\begin{gathered}
y \in R, x \operatorname{IeR}^{n} \\
A_{i} x=b_{i}, i=1, \ldots, m . \\
A_{i} x-\gamma \leq b_{i}, i=m_{e}+1, \ldots, m .
\end{gathered}
$$

The notation $\mathrm{A}_{i}$ indicates the $i$ th row of the matrix ' $\mathrm{A}$ ', and $\mathrm{b}$ is the coefficient vector.

Line Search and Merit Function. The QP sub-problem solution generates a vector, $\mathrm{dk}$, that is used to create a new iterate:

$$
\mathrm{xk}+1=\mathrm{xk}+\alpha \mathrm{dk}
$$

The phase length parameter $\alpha \mathrm{k}$ is set to cause an appropriate decrease in a merit function. Powell (1978) recommends setting the penalty parameter as:

$$
r_{i}=\left(r_{k+1}\right)_{i}=\max \left\{\frac{\left(r_{k}\right)_{i}+\lambda_{i}}{2}\right\}, i=1, \ldots, m .
$$

This allows for a positive involvement from constraints which are inactive in the QP solution, but which have been active recently.

$$
\operatorname{Ri}=\|\nabla f(x)\| / /\|\operatorname{gi}(x)\|
$$

where || || represents the Euclidean norm. It means greater contributions from constraints with lower gradients to the penalty parameter, which would be the case for active constraints at the point of solution.

\subsection{Heuristic Approach}

Numerous sources describe different evolutionary approaches to the problem. These are used due to the fact that in most cases, for the problem, it is very hard to get a solution, and therefore, in many cases, it is unsolvable. Some of the heuristic approaches available in the literature include Particle Swarm Optimization (PSO), Genetic Algorithm (GA) [5,24] and Genetic Programming (GP), and Artificial Bee Colony (ABC) [25].

PSO has a general disadvantage that it will fall into local optimal solution in high-dimension space and very low convergence rate during iteration or premature convergence [26]. With GA, choosing the right number of the population size and number of generations is also tough. Also, GA is a type of non-deterministic algorithm and in most of the cases, it provides a sub-optimal solution and may not be best suitable for multi-constrained optimization problems. With GP, the generation of mathematical formulations may be too difficult to interpret, as its combination of multiple elementary functions often results in extremely complex models. Another major issue is the selection of suitable parameter settings to control the algorithm run. Also, the time required for GP to converge to the global optimum is dependent on the parameters that govern the evolution process. One of the most popular heuristic algorithms used for multi-constrained optimization with a multi-input and multi-output system is Artificial Bee Colony optimization (ABC). Some of the advantages of $A B C$ over other algorithms 
include simplicity, flexibility, robustness, ability to explore local solutions, ease of implementation, and ability to handle the objective cost. Hence, this algorithm is used for the problem optimization and the details of the $\mathrm{ABC}$ algorithm are given below.

\section{Modified Artificial Bee Colony (MABC)-Based Optimisation}

The heuristic approach used for the optimization is the Modified Artificial Bee Colony (MABC) algorithm. In the MABC algorithm, a new search equation described by the global best guided $A B C$ inspired by PSO [27] has been utilized.

$\mathrm{MABC}$ overcomes the drawbacks of $\mathrm{ABC}$ and considers the global best information from the below equation.

$$
v i, j=x i, j+\Phi i, j(x i, j-x k, j)+\Psi i, j(y j-x i, j)
$$

where vi,j is the new neighboring food source, yj is the jth element of the global best solution, $\Psi \mathrm{i}, \mathrm{j}$ is a uniform random number in the range of 0 to $1.5, \Phi \mathrm{i}, \mathrm{j}$ is a random number in the range $[-1,1]$, and $\mathrm{j} \in\{1,2, \ldots, \mathrm{n}\}$ is a randomly chosen index.

The major steps of the MABC algorithm are outlined as follows:

Initialize all parameters,

Repeat while Termination criterions are not met.

Step 1. New food sources are computed in the Employee bee phase.

Step 2. Location of the food sources is updated based on their amount of nectar in the Onlooker Bee phase.

Step 3. Search the new food sources in place of rejected food sources in the Scout bee phase.

Step 4. Remember the best food source identified so far.

Step 5. End.

The output of the algorithm would be the best solution identified so far. The Modified ABC [25] is good at exploration but has a disadvantage of exploitation problems, which causes the algorithm to get trapped to local optima and it may not achieve the global optimal solution [23].

\section{Simulation and Analysis}

Wipke et al. [17] developed a National Renewable Energy Laboratory (NREL) MATLAB-based vehicle simulator called the ADVISOR tool for setting vehicle parameters for acceleration and grade tests with the required conditions. This tool provides the results for those tests and in addition to this, vehicle Fuel Consumption (FC) and emission parameters are also derived: HC, CO, and NOX. Gowrishankar and Nirmal [20] show how to fix the zero delta SOC correction technique with the tolerance limit, which is a very important step in PNGV constraints. This work analyzes the ECE-EUDC and FTP driving cycles.

The analysis is done with four different cases for two driving cycles, ECE-EUDC and FTP. Case 1 denotes results for the MABC algorithm with the FTP driving cycle, while Case 2 denotes the results for the same FTP driving cycle for the MABC-SQP algorithm. Whereas, Case 3 evaluates the MABC algorithm for the ECE-EUDC driving cycle and Case 4 explains the process of the ECE-EUDC driving cycle for the MABC-SQP algorithm. More weightage (50\%) is given to minimization of fuel utilization in Cases 1 and 2, and the remaining 50\% weightage is distributed among the other three emission vehicle parameters. In Cases 3 and 4, maximum weightage (70\%) is given for emission and the remaining 30\% weightage is kept for the fuel usage. The performance of the algorithm for various requirements of the vehicle is analyzed under these various objective functions with different weightage. Tony and Wipke [3] show the influences of the driving cycle on the peak speed and distance, with relation to the fuel consumption and emission. The optimal control problem setup is solved over the ECE-EUDC and FTP driving cycles, and the results are compared below to benchmark the proposed MABC + SQP 
algorithm over the MABC algorithm in finding the optimal solution. The analysis is done in two steps, namely MABC only and the MABC with SQP-Hessian approach.

\subsection{Modified Artificial Bee Colony Algorithm (MABC) FTP Driving Cycle}

Table 3 shows the corresponding initial input and optimized values obtained for the considered driving cycles for various cases for the FTP driving cycle for the MABC algorithm.

Table 3. Optimization results for the FTP driving cycle.

\begin{tabular}{|c|c|c|c|c|c|c|}
\hline \multicolumn{7}{|c|}{ FTP Driving Cycle MABC } \\
\hline & Items & Case 1 & Case 2 & Case 3 & Case 4 & Initial Value \\
\hline \multirow{10}{*}{ Variables } & FC_torque_scale & 1.351 & 1.400 & 1.400 & 1.458 & 1.349 \\
\hline & MC_torquescale & 0.714 & 0.783 & 1.100 & 1.076 & 1.182 \\
\hline & ESS_modulenumber & 27.741 & 30.000 & 27.000 & 28.000 & 30.000 \\
\hline & CS_ELSpeed_lo & 4.195 & 7.000 & 3.000 & 1.000 & 3.000 \\
\hline & CS_ELSpeed_hi & 19.595 & 23.000 & 31.000 & 18.000 & 20.000 \\
\hline & CS_min_trq_frac & 0.442 & 0.800 & 0.317 & 0.311 & 0.218 \\
\hline & CS_off_trq_frac & 0.051 & 0.069 & 0.050 & 0.139 & 0.137 \\
\hline & CS_lo_soc & 0.540 & 0.570 & 0.507 & 0.500 & 0.567 \\
\hline & CS_hi_soc & 0.753 & 0.650 & 0.617 & 0.680 & 0.695 \\
\hline & CS_charge torque & 13.890 & 31.000 & 25.000 & 31.000 & 31.000 \\
\hline \multirow{7}{*}{ Constraints } & Grade $(\%)$ & 8.547 & 8.322 & 8.260 & 8.891 & 7.200 \\
\hline & 0-60 mph time (s) & 8.080 & 7.976 & 8.453 & 8.152 & 8.400 \\
\hline & 40-60 mph time(s) & 3.796 & 3.730 & 4.097 & 3.886 & 4.000 \\
\hline & 0-85 mph (s) & 15.493 & 15.281 & 16.571 & 15.754 & 16.300 \\
\hline & Max speed (mph) & 129.02 & 129.960 & 126.200 & 129.030 & 127.000 \\
\hline & Max accel $\left(\mathrm{ft} / \mathrm{s}^{2}\right)$ & 16.400 & 16.400 & 16.400 & 16.400 & 16.400 \\
\hline & Distance in $5 \mathrm{~s}(\mathrm{ft})$ & 183.355 & 184.330 & 182.510 & 184.167 & 183.700 \\
\hline \multirow{4}{*}{ Objective } & FC (mpg) & 35.890 & 35.600 & 33.701 & 33.958 & 32.200 \\
\hline & HC (g/mile) & 0.539 & 0.574 & 0.571 & 0.587 & 0.564 \\
\hline & CO (g/mile) & 2.236 & 2.639 & 2.504 & 2.519 & 3.244 \\
\hline & NOx (g/mile) & 0.418 & 0.460 & 0.459 & 0.457 & 0.471 \\
\hline
\end{tabular}

Figures 4 and 5 show the vehicle performance change after optimization of its design with the MABC approach for the FTP driving cycle, Case 1. Figure 4 shows the battery SOC variation with respect to the driving cycle, and it can be observed from the figure that variation between the initial and final value of battery SOC is less than $0.5 \%$ and SOC value lies close to $59 \%$.

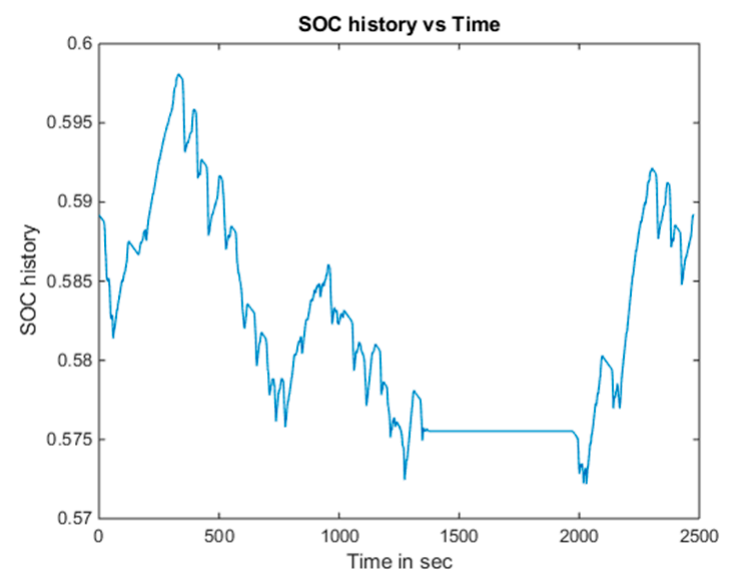

Figure 4. State of Charge (SOC) history. 


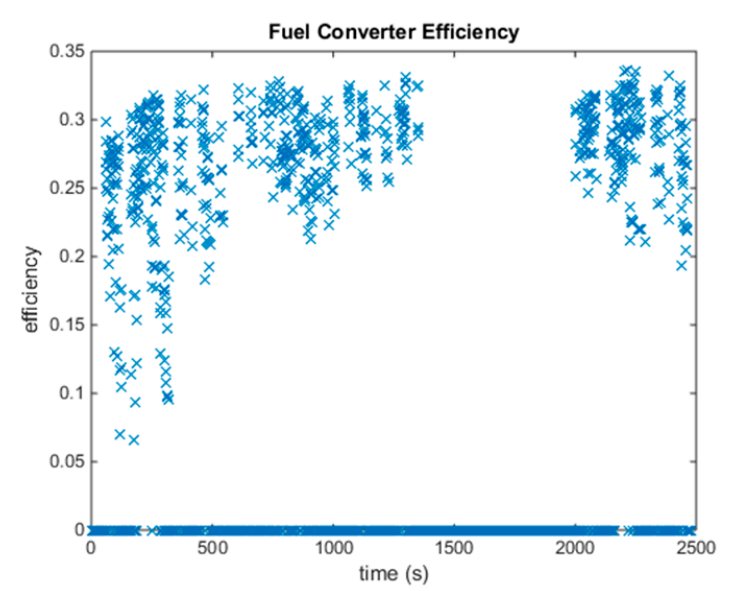

Figure 5. Fuel convertor efficiency.

Figure 5 shows fuel converter efficiency and as it is seen from the figure, there is no big impact and the efficiency is maintained at around $27 \%$. Because of the large variation of speeds ranging from idle to nearing $60 \mathrm{mph}$ top speed in this driving cycle, the loss at lower speeds is compensated. Figure 6 shows the electric motor torque-speed characteristics and also the limits of maximum motoring and regeneration torque. At lower $\mathrm{rpm}$, the torque points lie more on the positive region, supplementing the engine operation, and at rpm greater than 2000, torque points also shift to the negative region due to regeneration operation.

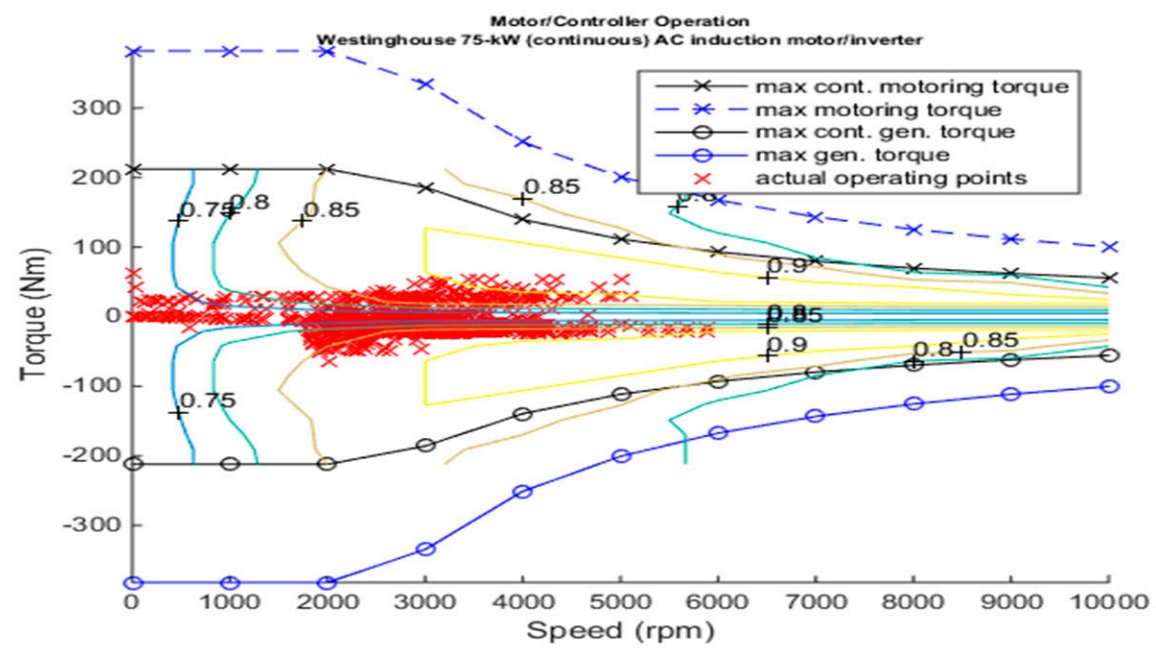

Figure 6. Motor torque-speed.

Also, Figures 7 and 8 show energy utilization of different key components of the vehicle during power mode and regeneration mode of the vehicle. It can be observed from these figures that the energy utilized by the fuel converter is higher during the power mode, which is about $28,000 \mathrm{~kJ}$, and energy utilized by the motor controller is higher, $1200 \mathrm{~kJ}$, during regeneration mode, in order to recharge the battery and keep it within the intended SOC level. Additionally, it can be seen that although the efficiency of the fuel converter is around $27 \%$ only, which is similar to the previous case, the energy loss has been reduced after optimization. Also, energy usage by braking components is also near to $1400 \mathrm{~kJ}$ in this mode, to support higher energy regeneration. 


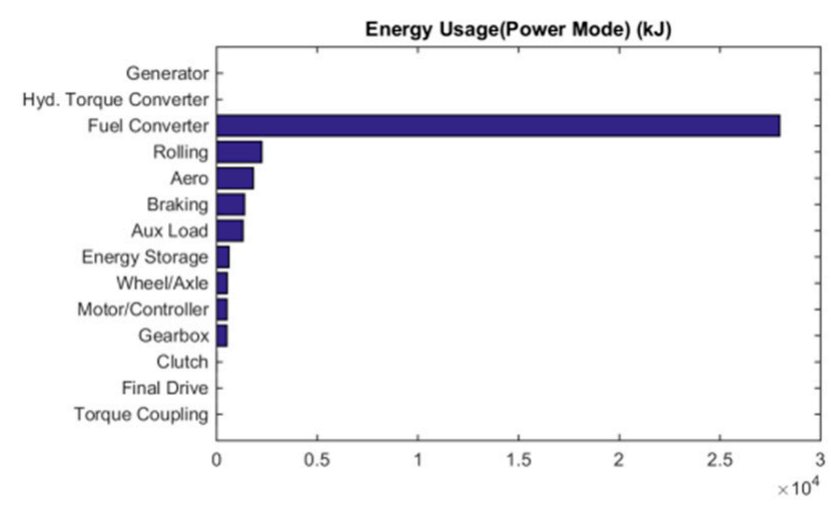

Figure 7. Energy use power mode.

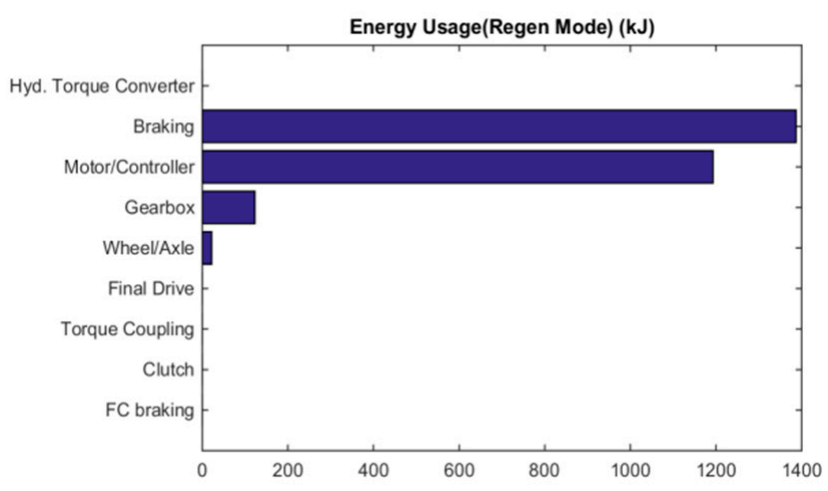

Figure 8. Energy use regeneration (regen) mode.

\subsection{Modified Artificial Bee Colony + Sequential Programming Algorithm (MABC + SQP) FTP Driving Cycle}

In order to obtain a balance between the exploration and exploitation issues and to overcome the same, a combined approach of using MABC as a global optimizer for exploration and SQP as a deterministic local search for exploitation has been used. The results show that with reduced emissions and still with an improved fuel economy compared to the initial design, as shown in the results for most of the cases, the proposed MABC with SQP-Hessian approach shows its superiority in finding an optimal solution compared to the other individual heuristic approach. Table 4 shows the corresponding initial input and optimized values obtained for the considered driving cycles for various cases of the $\mathrm{MABC}+\mathrm{SQP}$ algorithm.

It is evident from the above Tables 3 and 4 that the solutions obtained for different cases are according to the weightage of FC for different cases. As for Cases 1 and 2, they have been set with a higher weightage value for FC, and the improvement in FC in mpg is also high when compared to Cases 3 and 4 .

Figures 9 and 10 show the vehicle performance change after optimization of its design with the MABC approach for the FTP driving cycle, Case 1. Figure 9 shows the battery SOC variation with respect to the driving cycle, and it can be observed from the figure that variation between the initial and final value of battery SOC is less than $0.5 \%$ and SOC value lies close to $57 \%$.

Figure 10 shows fuel converter efficiency and as it is seen from the figure, there is no big impact and the efficiency is maintained around $26 \%$. Because of the large variation of speeds ranging from idle to nearing $60 \mathrm{mph}$ top speed in this driving cycle, the loss at lower speeds is compensated. Figure 11 depicts the electric motor torque-speed characteristics and also, the limits of maximum motoring and regeneration torque. At lower $\mathrm{rpm}$, the torque points lie more on the positive region, supplementing the engine operation, and at rpm greater than 2000, torque points also shift to the negative region due to regeneration operation. 
Table 4. Optimization results of FTP driving cycle for MABC + SQP.

\begin{tabular}{|c|c|c|c|c|c|c|}
\hline \multicolumn{7}{|c|}{ FTP Driving Cycle, MABC + SQP } \\
\hline & Items & Case 1 & Case 2 & Case 3 & Case 4 & Initial Value \\
\hline \multirow{10}{*}{ Variables } & FC_torque_scale & 1.400 & 1.351 & 1.400 & 1.458 & 1.349 \\
\hline & MC_torquescale & 0.783 & 0.714 & 1.100 & 1.076 & 1.182 \\
\hline & ESS_modulenumber & 29.010 & 27.741 & 27.000 & 28.000 & 30.000 \\
\hline & CS_ELSpeed_lo & 7.000 & 4.195 & 3.000 & 1.000 & 3.000 \\
\hline & CS_ELSpeed_hi & 23.000 & 19.595 & 31.000 & 18.000 & 20.000 \\
\hline & CS_min_trq_frac & 0.485 & 0.442 & 0.317 & 0.311 & 0.218 \\
\hline & CS_off_trq_frac & 0.069 & 0.051 & 0.050 & 0.139 & 0.137 \\
\hline & CS_lo_soc & 0.381 & 0.540 & 0.507 & 0.500 & 0.567 \\
\hline & CS_hi_soc & 0.660 & 0.753 & 0.617 & 0.680 & 0.695 \\
\hline & CS_charge torque & 31.00 & 13.890 & 25.000 & 31.000 & 31.000 \\
\hline \multirow{7}{*}{ Constraints } & Grade (\%) & 8.964 & 8.547 & 8.260 & 8.891 & 7.200 \\
\hline & 0-60 mph time (s) & 8.515 & 8.080 & 8.453 & 8.152 & 8.400 \\
\hline & 40-60 mph time (s) & 4.105 & 3.796 & 4.097 & 3.886 & 4.000 \\
\hline & 0-85 mph (s) & 16.68 & 15.493 & 16.571 & 15.754 & 16.300 \\
\hline & Max speed (mph) & 125.551 & 129.02 & 126.200 & 129.030 & 127.000 \\
\hline & Max accel $\left(\mathrm{ft} / \mathrm{s}^{2}\right)$ & 16.4 & 16.400 & 16.400 & 16.400 & 16.400 \\
\hline & Distance in $5 \mathrm{~s}(\mathrm{ft})$ & 181.133 & 183.355 & 182.510 & 184.167 & 183.700 \\
\hline \multirow{4}{*}{ Objective } & FC (mpg) & 36.098 & 35.890 & 33.701 & 33.958 & 32.200 \\
\hline & HC (g/mile) & 0.578 & 0.539 & 0.571 & 0.587 & 0.564 \\
\hline & CO (g/mile) & 2.625 & 2.236 & 2.504 & 2.519 & 3.244 \\
\hline & NOx (g/mile) & 0.465 & 0.418 & 0.459 & 0.457 & 0.471 \\
\hline
\end{tabular}

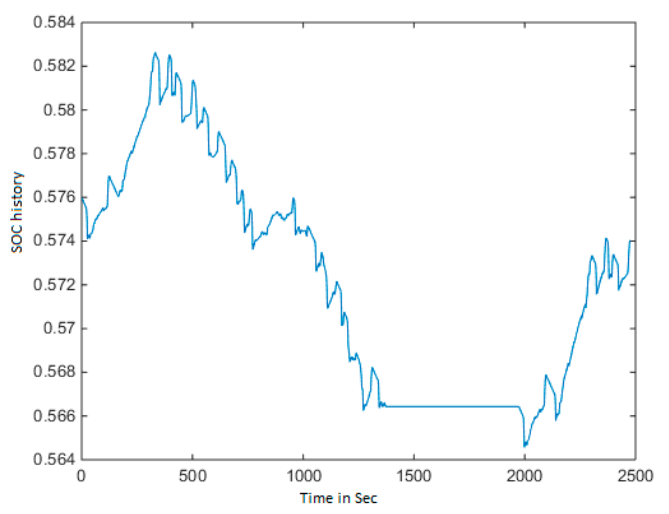

Figure 9. SOC history.

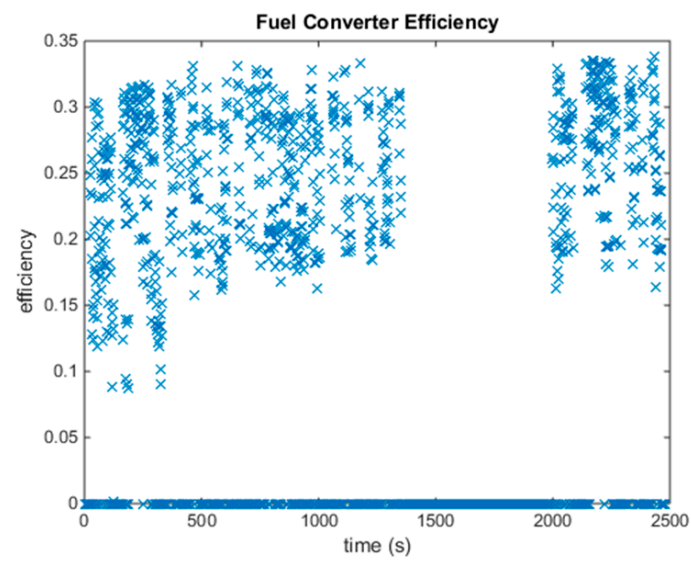

Figure 10. Fuel convertor efficiency. 


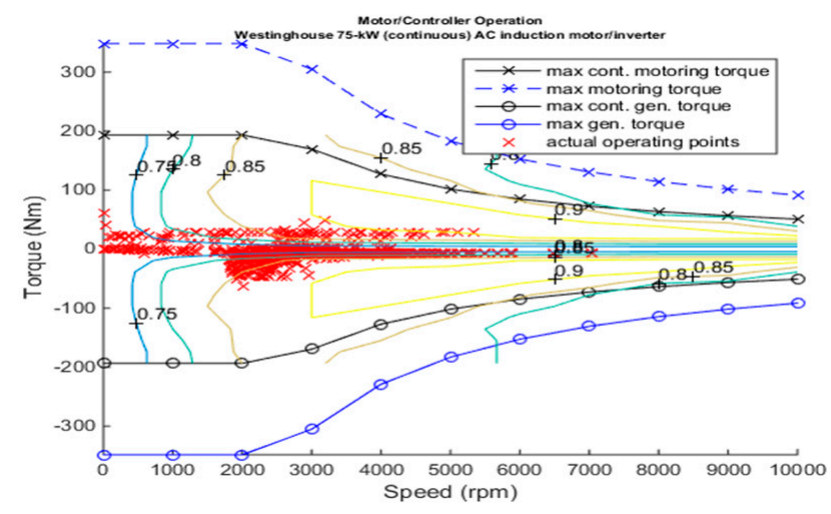

Figure 11. Motor torque-speed.

Additionally, Figures 12 and 13 show the energy utilization of different key components of the vehicle during power mode and regeneration mode of the vehicle. It can be observed from these figures that the energy utilized by the fuel converter is higher during the power mode, which is about $27,000 \mathrm{~kJ}$, and energy utilized by the motor controller is higher, $1300 \mathrm{~kJ}$, during regeneration mode, in order to recharge the battery and keep it within the intended SOC level. Moreover, it can be seen that although the efficiency of the fuel converter is around $26 \%$ only, which is similar to the previous case, the energy loss has been reduced after optimization. Also, energy usage by braking components is also near to $1400 \mathrm{~kJ}$ in this mode, to support higher energy regeneration.

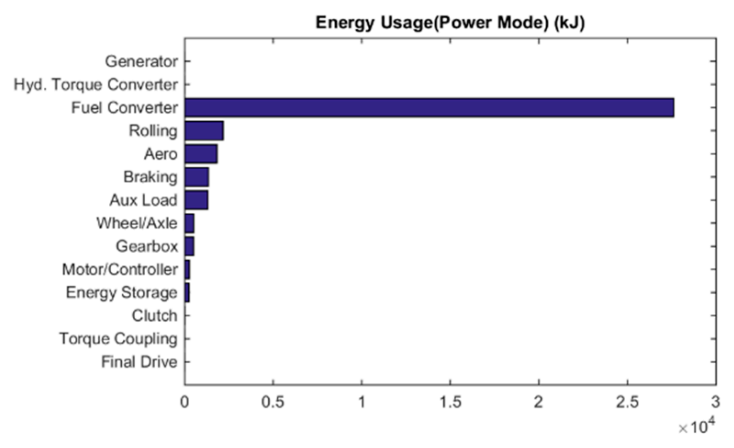

Figure 12. Energy use power mode.

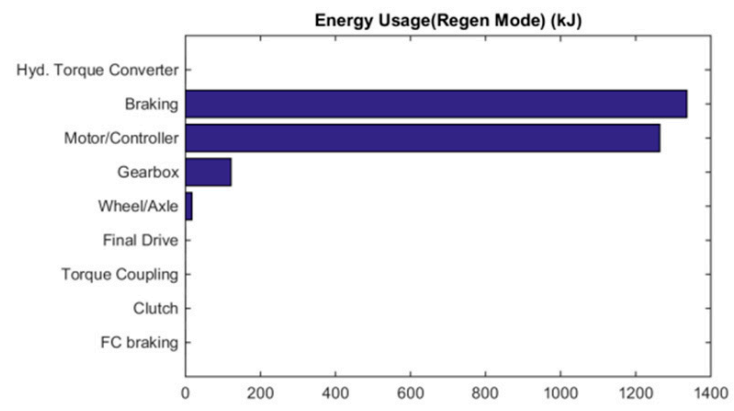

Figure 13. Energy use regeneration (regen) mode.

\subsection{Modified Artificial Bee Colony Algorithm (MABC) ECE EUDC Driving Cycle}

Table 5 shows the ECE-EUDC driving cycle for the MBAC algorithm.

Figures 14 and 15 show the vehicle performance change after optimization of its design with the MABC + SQP approach for the ECE-EUDC driving cycle, Case 1. Figure 14 shows the battery 
SOC variation with respect to the driving cycle, and it can be observed from the figure that variation between the initial and final value of battery SOC is less than $0.5 \%$ and SOC value lies close to $39 \%$.

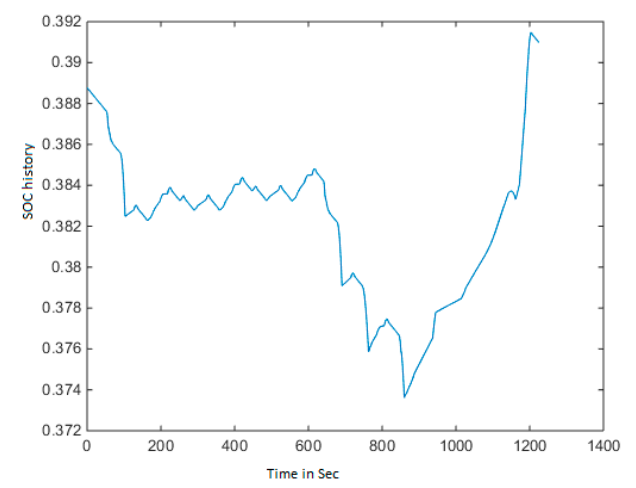

Figure 14. SOC history.

Table 5. Optimization results for ECE-EUDC MABC.

\begin{tabular}{|c|c|c|c|c|c|c|}
\hline \multicolumn{7}{|c|}{ ECE EUDC Driving Cycle MABC } \\
\hline & Items & Case 1 & Case 2 & Case 3 & Case 4 & Initial Value \\
\hline \multirow{10}{*}{ Variables } & FC_torque_scale & 1.190 & 1.200 & 1.300 & 1.210 & 1.349 \\
\hline & MC__torquescale & 0.783 & 0.811 & 0.700 & 0.834 & 1.182 \\
\hline & ESS_modulenumber & 30.000 & 30.000 & 23.000 & 28.000 & 30.000 \\
\hline & CS_ELSpeed_lo & 8.000 & 8.000 & 4.330 & 6.751 & 3.000 \\
\hline & CS_ELSpeed_hi & 11.000 & 11.000 & 30.000 & 19.665 & 20.000 \\
\hline & CS_min_trq_frac & 0.100 & 0.723 & 0.246 & 0.534 & 0.218 \\
\hline & CS_off_trq_frac & 0.183 & 0.183 & 0.211 & 0.162 & 0.137 \\
\hline & CS_lo_soc & 0.520 & 0.516 & 0.223 & 0.158 & 0.567 \\
\hline & CS_hi_soc & 0.850 & 0.845 & 0.727 & 0.611 & 0.695 \\
\hline & CS_charge torque & 36.000 & 35.000 & 5.200 & 39.118 & 31.000 \\
\hline \multirow{7}{*}{ Constraints } & Grade $(\%)$ & 7.565 & 7.606 & 9.075 & 8.015 & 7.200 \\
\hline & 0-60 mph time (s) & 8.964 & 8.954 & 9.221 & 9.704 & 8.400 \\
\hline & 40-60 mph time (s) & 4.451 & 4.444 & 4.595 & 4.934 & 4.000 \\
\hline & 0-85 mph (s) & 18.105 & 18.071 & 18.675 & 19.935 & 16.300 \\
\hline & Max speed (mph) & 120.456 & 120.678 & 119.172 & 119.385 & 127.000 \\
\hline & $\operatorname{Max}$ accel $\left(\mathrm{ft} / \mathrm{s}^{2}\right)$ & 16.4 & 16.4 & 16.4 & 16.4 & 16.400 \\
\hline & Distance in $5 \mathrm{~s}(\mathrm{ft})$ & 180.665 & 180.761 & 178.23 & 176.349 & 183.700 \\
\hline \multirow{4}{*}{ Objective } & FC (mpg) & 33.558 & 33.357 & 29.291 & 32.667 & 28.600 \\
\hline & HC (g/mile) & 0.724 & 0.729 & 0.736 & 0.736 & 0.768 \\
\hline & CO (g/mile) & 3.148 & 3.124 & 2.566 & 3.735 & 3.157 \\
\hline & NOx (g/mile) & 0.482 & 0.486 & 0.436 & 0.508 & 0.495 \\
\hline
\end{tabular}

Figure 15 shows fuel converter efficiency and as it is seen from the figure, there is no big impact and the efficiency is maintained at around $24 \%$. Because of the large variation of speeds ranging from idle to nearing $75 \mathrm{mph}$ top speed in this driving cycle, the loss at lower speed is compensated.

Figure 16 shows the electric motor torque-speed characteristics and also the limits of maximum motoring and regeneration torque. At lower $\mathrm{rpm}$, the torque points lie more on the positive region, supplementing the engine operation, and at rpm greater than 2000, torque points also shift to the negative region due to regeneration operation. Also, Figures 17 and 18 show energy utilization of different key components of the vehicle during power mode and regeneration mode of the vehicle. It can be observed from these figures that the energy utilized by the fuel converter is higher during the power mode, which is about 20,000 kJ, and energy utilized by the motor controller is higher, $1000 \mathrm{~kJ}$, during regeneration mode, in order to recharge the battery and keep it within the intended SOC level. It can be seen that although the efficiency of the fuel converter is around $24 \%$ only, which is similar to 
the previous case, the energy loss has been reduced after optimization [28]. Also, energy usage by braking components is also near to $500 \mathrm{~kJ}$ in this mode, to support higher energy regeneration.

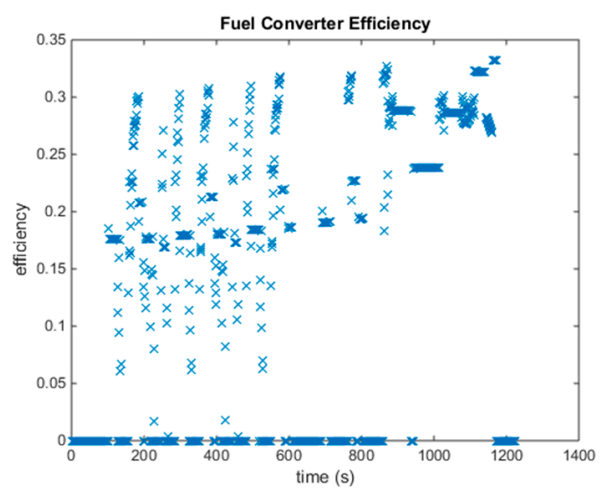

Figure 15. Fuel converter efficiency.

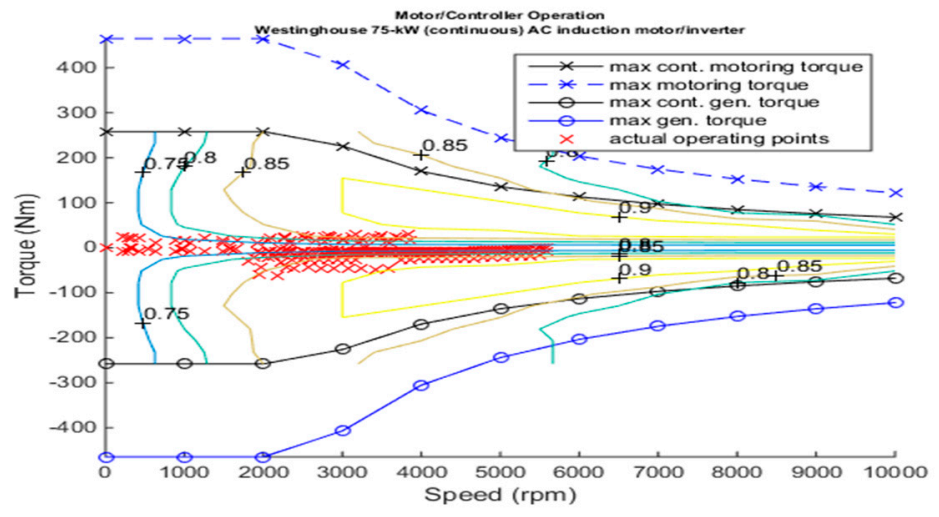

Figure 16. Motor torque-speed.

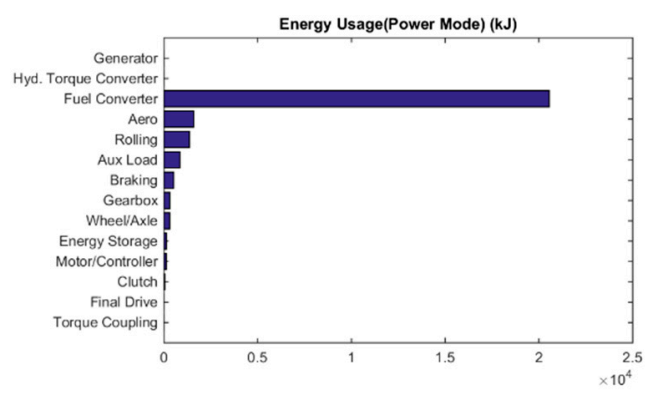

Figure 17. Energy use power mode.

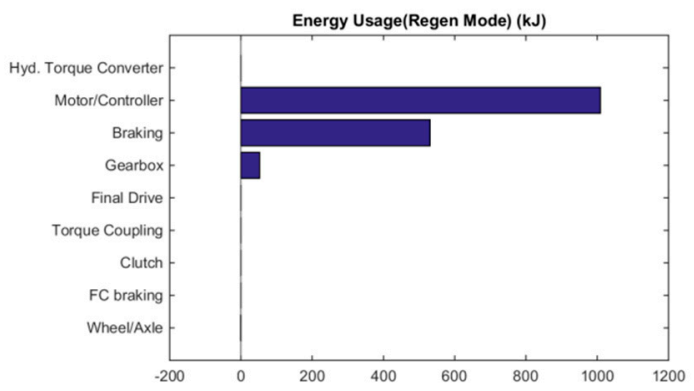

Figure 18. Energy use regeneration (regen) mode. 


\subsection{Modified Artificial Bee Colony Algorithm $(M A B C+S Q P)$ ECE EUDC Driving Cycle}

Figures 19 and 20 show the vehicle performance change after optimization of its design with the MABC approach for the ECE-EUDC driving cycle, Case 1. Figure 19 shows the battery SOC variation with respect to the driving cycle, and it can be observed from the figure that variation between the initial and final value of battery SOC is less than $0.5 \%$ and SOC value lies close to $64 \%$.

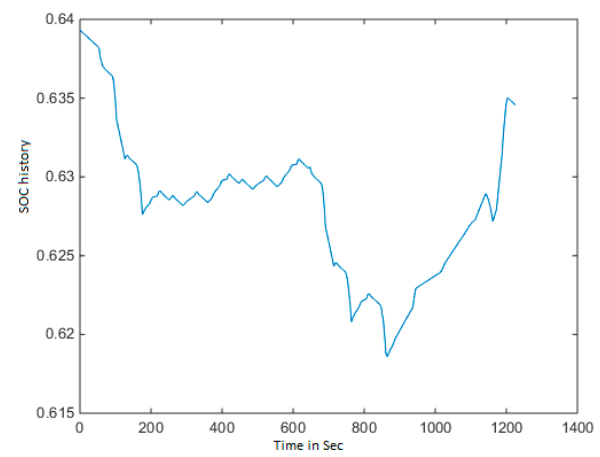

Figure 19. SOC history.

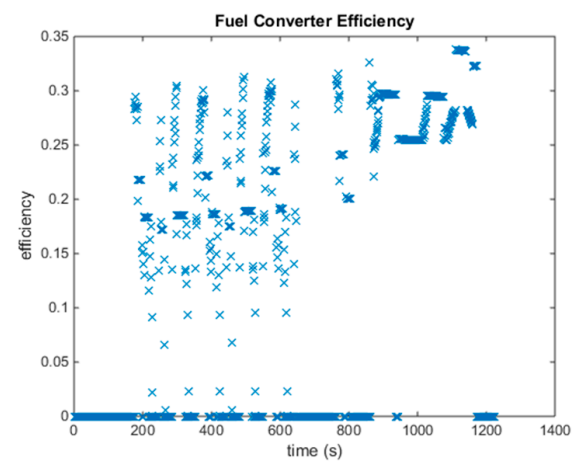

Figure 20. Fuel converter efficiency.

Figure 21 illustrates the electric motor torque-speed characteristics and also the limits of maximum motoring and regeneration torque. At lower rpm, the torque points lie more on the positive region, supplementing the engine operation, and at rpm greater than 2000, torque points also shift to the negative region due to regeneration operation.

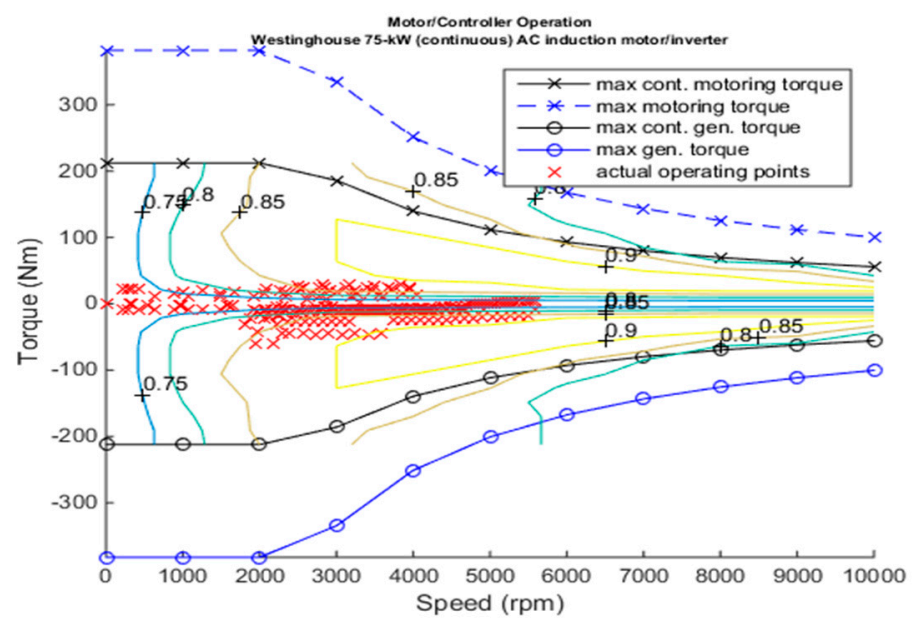

Figure 21. Motor torque-speed. 
Moreover, Figures 22 and 23 represent the energy utilization of different key components of the vehicle during power mode and regeneration mode of the vehicle. It can be observed from these figures that the energy utilized by the fuel converter is higher during the power mode, which is about $19,000 \mathrm{~kJ}$, and energy utilized by the motor controller is close to $800 \mathrm{~kJ}$ during regeneration mode, in order to recharge the battery and keep it within the intended SOC level. Also, it can be seen that although the efficiency of the fuel converter is around $24 \%$ only, which is similar to the previous case, the energy loss has been reduced after optimization. Furthermore, energy usage by braking components is also near to $550 \mathrm{~kJ}$ in this mode, to support higher energy regeneration.

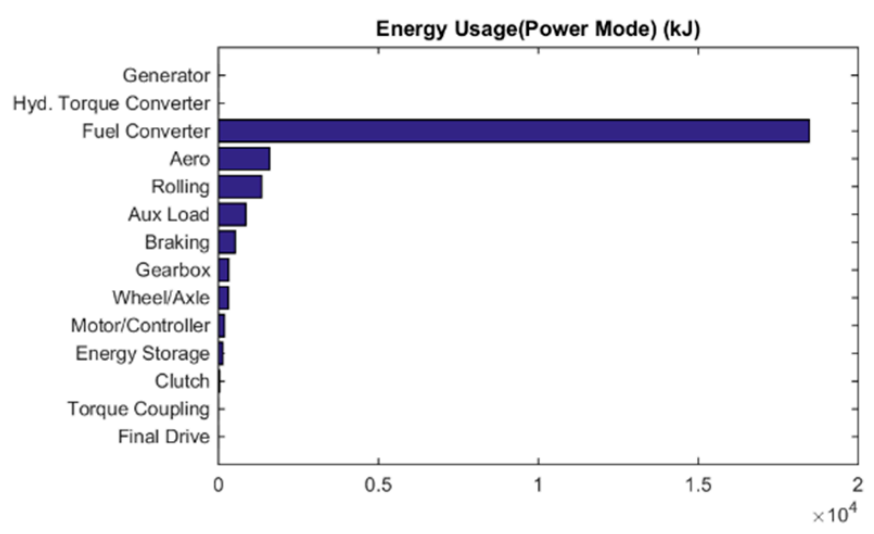

Figure 22. Energy use power mode.

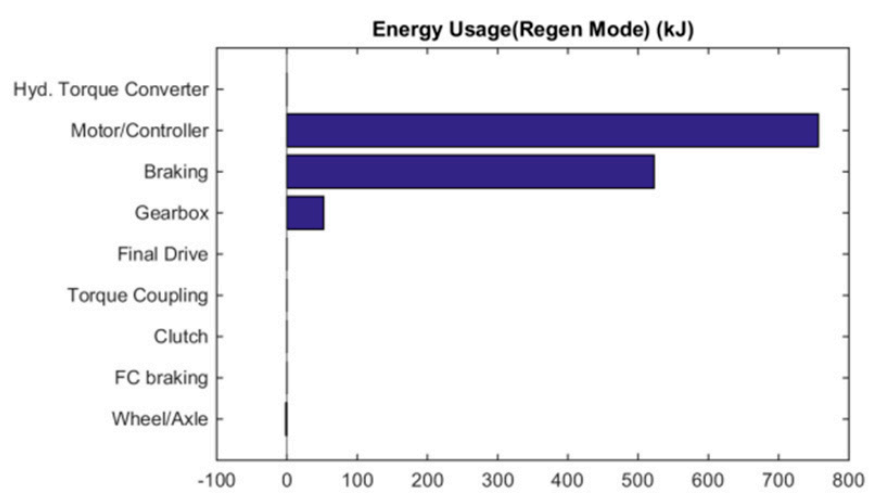

Figure 23. Energy use regeneration (regen) mode.

\subsection{Inference}

The result for BABC has been referred from this work [20] as it was also using similar vehicle configuration. To illustrate the improvement in the vehicle performance after optimization, Case 1 results of all the three methods discussed above are tabulated below for comparison. Tables 6-8 show the comparative analysis for the two driving cycles and its units for the constraints are already mentioned in the respective tables. As seen from Tables 6-8, there is a significant increase in the fuel consumption in terms of miles per gallon. This shows that the combined MABC + SQP method can obtain superior results in terms of vehicle performance compared to other methods. Similarly, for the other cases, based on the weightage of the variables, either the fuel efficiency would be increased, or the emissions would be reduced, as discussed in the previous section. 
Table 6. Results of ECE-EUDC driving cycle for MABC + SQP.

\begin{tabular}{|c|c|c|c|c|c|c|}
\hline \multicolumn{7}{|c|}{ ECE-EUDC Driving Cycle, MABC + SQP } \\
\hline & Items & Case 1 & Case 2 & Case 3 & Case 4 & Initial Value \\
\hline \multirow{10}{*}{ Variables } & FC_torque_scale & 1.050 & 1.200 & 1.198 & 1.300 & 1.349 \\
\hline & MC_torquescale & 0.967 & 0.548 & 0.832 & 0.700 & 1.182 \\
\hline & ESS_modulenumber & 29.010 & 22.971 & 28.950 & 29.000 & 30.000 \\
\hline & CS_ELSpeed_lo & 4.000 & 4.302 & 6.979 & 7.6000 & 3.000 \\
\hline & CS_ELSpeed_hi & 19.000 & 29.955 & 12.920 & 14.000 & 20.000 \\
\hline & CS_min_trq_frac & 0.485 & 0.444 & 0.331 & 0.678 & 0.218 \\
\hline & CS_off_trq_frac & 0.154 & 0.090 & 0.086 & 0.110 & 0.137 \\
\hline & CS_lo_soc & 0.567 & 0.386 & 0.322 & 0.523 & 0.567 \\
\hline & CS_hi_soc & 0.844 & 0.742 & 0.730 & 0.727 & 0.695 \\
\hline & CS_charge torque & 31.000 & 15.822 & 29.994 & 32.000 & 31.000 \\
\hline \multirow{7}{*}{ Constraints } & Grade (\%) & 73.340 & 8.076 & 7.810 & 8.097 & 7.200 \\
\hline & 0-60 mph time (s) & 8.889 & 9.066 & 8.879 & 8.141 & 8.400 \\
\hline & 40-60 mph time (s) & 4.378 & 4.463 & 4.374 & 3.842 & 4.000 \\
\hline & 0-85 mph (s) & 17.883 & 18.221 & 17.745 & 15.677 & 16.300 \\
\hline & Max speed (mph) & 119.905 & 119.268 & 121.298 & 127.922 & 127.000 \\
\hline & $\operatorname{Max}$ accel $\left(\mathrm{ft} / \mathrm{s}^{2}\right)$ & 16.400 & 16.400 & 16.400 & 16.400 & 16.400 \\
\hline & Distance in $5 \mathrm{~s}(\mathrm{ft})$ & 179.700 & 177.819 & 180.179 & 180.179 & 183.700 \\
\hline \multirow{4}{*}{ Objective } & FC (mpg) & 34.484 & 34.447 & 32.048 & 32.048 & 28.600 \\
\hline & HC (g/mile) & 0.621 & 0.713 & 0.690 & 0.690 & 0.768 \\
\hline & $\mathrm{CO}(\mathrm{g} / \mathrm{mile})$ & 3.183 & 2.705 & 2.905 & 2.905 & 3.157 \\
\hline & NOx (g/mile) & 0.442 & 0.459 & 0.470 & 0.470 & 0.495 \\
\hline
\end{tabular}

Table 7. Comparison of the FTP driving cycle for the BABC, MABC, and MABC + SQP methods.

\begin{tabular}{|c|c|c|c|c|c|}
\hline & Items & $\begin{array}{l}\text { BABC } \\
\text { Case } 1\end{array}$ & $\begin{array}{l}\text { MABC } \\
\text { Case } 1\end{array}$ & $\begin{array}{l}\text { MABC + SQP } \\
\text { Case } 1\end{array}$ & Initial Value \\
\hline \multirow{10}{*}{ Variables } & FC_torque_scale & 1.500 & 1.351 & 1.400 & 1.349 \\
\hline & MC_torquescale & 0.783 & 0.714 & 0.783 & 1.182 \\
\hline & ESS_modulenumber & 30.000 & 27.741 & 29.010 & 30.000 \\
\hline & CS_ELSpeed_lo & 8.000 & 4.195 & 7.000 & 3.000 \\
\hline & CS_ELSpeed_hi & 22.000 & 19.595 & 23.000 & 20.000 \\
\hline & CS_min_trq_frac & 0.800 & 0.442 & 0.485 & 0.218 \\
\hline & CS_off_trq_frac & 0.069 & 0.051 & 0.069 & 0.137 \\
\hline & CS_lo_soc & 0.570 & 0.540 & 0.381 & 0.567 \\
\hline & CS_hi_soc & 0.650 & 0.753 & 0.660 & 0.695 \\
\hline & CS_charge torque & 31.000 & 13.890 & 31.00 & 31.000 \\
\hline \multirow{7}{*}{ Constraints } & Grade (\%) & 9.057 & 8.547 & 8.964 & 7.200 \\
\hline & 0-60 mph time (s) & 7.841 & 8.735 & 8.515 & 8.400 \\
\hline & $40-60 \mathrm{mph}$ time(s) & 3.633 & 4.287 & 4.105 & 4.000 \\
\hline & 0-85 mph (s) & 14.882 & 17.381 & 16.68 & 16.300 \\
\hline & Max speed (mph) & 131.01 & 123.16 & 125.551 & 127.000 \\
\hline & Max accel $\left(\mathrm{ft} / \mathrm{s}^{2}\right)$ & 16.400 & 16.400 & 16.4 & 16.400 \\
\hline & Distance in $5 \mathrm{~s}(\mathrm{ft})$ & 185.04 & 181.75 & 181.133 & 183.700 \\
\hline \multirow{4}{*}{ Objective } & FC (mpg) & 34.857 & 35.890 & 36.098 & 32.200 \\
\hline & $\mathrm{HC}$ (g/mile) & 0.605 & 0.539 & 0.578 & 0.564 \\
\hline & $\mathrm{CO}(\mathrm{g} / \mathrm{mile})$ & 2.522 & 2.236 & 2.625 & 3.244 \\
\hline & NOx (g/mile) & 0.472 & 0.418 & 0.465 & 0.471 \\
\hline
\end{tabular}


Table 8. Comparison of the ECE EUDC driving cycle for the BABC, MABC, and MABC + SQP methods.

\begin{tabular}{cccccc}
\hline & Items & BABC & MABC \\
Case 1 & Case 1 & $\begin{array}{c}\text { MABC + SQP } \\
\text { Case 1 }\end{array}$ & Initial Value \\
\hline \multirow{6}{*}{ Variables } & FC_torque_scale & 1.315 & 1.190 & 1.050 & 1.349 \\
& MC_torquescale & 0.952 & 0.783 & 0.967 & 1.182 \\
& ESS_modulenumber & 29.000 & 30.000 & 29.010 & 30.000 \\
& CS_ELSpeed_lo & 7.000 & 8.000 & 4.000 & 3.000 \\
& CS_ELSpeed_hi & 12.902 & 11.000 & 19.000 & 20.000 \\
& CS_min_trq_frac & 0.259 & 0.100 & 0.485 & 0.218 \\
& CS_off_trq_frac & 0.002 & 0.183 & 0.154 & 0.137 \\
& CS_lo_soc & 0.261 & 0.520 & 0.567 & 0.567 \\
& CS_hi_soc & 0.655 & 0.850 & 0.844 & 0.695 \\
& CS_charge torque & 30.000 & 36.000 & 31.000 & 31.000 \\
\hline \multirow{5}{*}{ Constraints } & Grade (\%) & 8.526 & 7.565 & 73.340 & 7.200 \\
& 0-60 mph time (s) & 9.231 & 8.964 & 8.889 & 8.400 \\
& 40-60 mph time (s) & 4.614 & 4.451 & 4.378 & 4.000 \\
& 0-85 mph (s) & 18.618 & 18.105 & 17.883 & 16.300 \\
& Max speed (mph) & 120.897 & 120.456 & 119.905 & 127.000 \\
& Max accel (ft/s $\left.{ }^{2}\right)$ & 16.4 & 16.400 & 16.400 & 16.400 \\
& Distance in 5 s (ft) & 178.297 & 180.665 & 179.700 & 183.700 \\
\hline \multirow{5}{*}{ Objective } & FC (mpg) & 30.387 & 33.558 & 34.484 & 28.600 \\
& HC (g/mile) & 0.74 & 0.724 & 0.621 & 0.768 \\
& CO (g/mile) & 2.857 & 3.148 & 3.183 & 3.157 \\
& NOx (g/mile) & 0.474 & 0.482 & 0.442 & 0.495 \\
\hline
\end{tabular}

\section{Conclusions}

The design of a parallel HEV involves a number of variables that must be optimized for better fuel economy and vehicle performance. Driving cycle pattern also plays a key role in assessing the fuel economy and emissions. The objective of this study was to minimize the overall fuel consumption of a parallel HEV on FTP and ECE-EUDC driving cycles to improve the vehicle performance. The weighting factors also have the influence on determining the parameters for the vehicle performance. In this research, a hybrid MABC with SQP approach was proposed to obtain better optimal solutions. This method was analyzed with various boundary conditions and PNGV constraints, which occur in every driving cycle and test case. From the test cases, the performance of HEV and its PNGV constraints were analyzed. From the results, it was clearly indicated that the proposed approach achieved an increased fuel economy of $12 \%$ for FTP and 20\% for ECE-EUDC driving cycles. In most of the cases, the size of the Energy Storage System (ESS) components were minimized, which will decrease the overall cost of the HEV in parallel. Furthermore, the proposed MABC-SQP approach decreased one of the engine emission parameters, HC, up to $19 \%$ for the ECE-EUDC driving cycle. While considering the FTP driving cycle, the engine emission parameter $\mathrm{CO}$ was decreased up to $19 \%$. While considering the SOC portion, the change was within $0.5 \%$ tolerance on every solution with reduced battery modules, which satisfies the required vehicle performance. While comparing the results of the individual heuristic approach [20], the proposed MABC + SQP approach achieved better results, as indicated above. Also, in comparison to a MABC algorithm, the hybrid MABC + SQP solution was found to be outstanding in that it achieved remarkable real-time fuel savings and reduced emissions, with no significant penalties for final battery charging and reduced size of key vehicle components for different driving cycles.

Author Contributions: Methodology, formal analysis, and investigation, S.N.S.; software, resources, and data curation, S.K.; data collection and validation, S.P.; writing —original draft preparation and review and editing, R.P.d.P.; supervision and project administration, B.D.P. All authors have read and agreed to the published version of the manuscript.

Funding: This research received no external funding.

Conflicts of Interest: The authors declare no conflict of interest. 


\section{Nomenclature}

\begin{tabular}{|c|c|}
\hline General & \\
\hline $\mathrm{ABC}$ & Artificial Bee Colony \\
\hline ADVISOR & Advanced Vehicle Simulator \\
\hline $\mathrm{CO}$ & Carbon Monoxide \\
\hline EACS & Electric Assist Control Strategy \\
\hline ECE-EUDC & Economic commission Europe - Extra Urban Driving Cycle \\
\hline FC & Fuel Consumption \\
\hline FTP & Federal Test Procedure \\
\hline $\mathrm{HC}$ & Hydrocarbons \\
\hline $\mathrm{HEV}$ & Hybrid Electric Vehicle \\
\hline ICE & Internal Combustion Engine \\
\hline NEDC & New European Driving Cycle \\
\hline NOX & Oxides of Nitrogen \\
\hline NREL & National Renewable Energy Laboratory \\
\hline PMP & Pontryagins Minimum Principle \\
\hline PNGV & Partnership for a New Generation of Vehicles \\
\hline PSO & Particle Swarm Optimization \\
\hline SI & Spark Ignition \\
\hline SOC & State of Charge \\
\hline SQP & Sequential Quadratic Programming \\
\hline UDDS & Urban Dynamometer Driving Schedule \\
\hline VRLA & Valve Regulated Lead Acid \\
\hline Notations & \\
\hline$\alpha$ & Distance to constraint boundaries in SQP \\
\hline $\mathrm{d}^{\wedge} \mathrm{k}$ & Search direction variable for SQP \\
\hline$\lambda \mathrm{K}$ & Lagrange multipliers \\
\hline $\mathrm{L}(\mathrm{x}, \lambda)$ & Lagrangian function \\
\hline Pmot & Motor Mechanical power (W) \\
\hline Pengine & Engine power $(\mathrm{W})$ \\
\hline Pengine_max_power & Maximum Engine power (W) \\
\hline
\end{tabular}

\section{References}

1. Zhang, P.; Yan, F.; Du, C. A comprehensive analysis of energy management strategies for hybrid electric vehicles based on bibliometrics. Renew. Sustain. Energy Rev. 2015, 48, 88-104. [CrossRef]

2. Sebastien, D.; Lauber, J.; Marie, T.; Rimaux, J. Control of Parallel Hybrid Powertrain: Optimal Control. IEEE Trans. Veh. Technol. 2004, 53, 772-781.

3. Tony, M.; Wipke, K. Modelling Grid-Connected Hybrid Electric Vehicles Using ADVISOR. In Proceedings of the Sixteenth Annual Battery Conference on Applications and Advances, Long Beach, CA, USA, 12 January 2001.

4. Wu, X.; Guifang, G.; Xu, J.; Cao, B. Application of Parallel Chaos Optimization Algorithm for Plug-in Hybrid Electric Vehicle Design. Int. J. Bifurc. Chaos 2014, 24. [CrossRef]

5. Chirag, D. Design and Optimization of Hybrid Electric Vehicle Drivetrain and Control Strategy Parameters Using Evolutionary Algorithms. Master's Thesis, Concordia University, Montréal, QC, Canada, 2010.

6. Valerie, J.H.; Wipke, K.B.; Rausen, D.J. HEV Control Strategy for Real-Time Optimization of Fuel Economy and Emission. Soc. Automot. Eng. 2000. [CrossRef]

7. Enang, W.; Bannister, C.; Brace, C.; Vagg, C. Modelling and Heuristic control of a Parallel Hybrid Electric Vehicle. Proc. Inst. Mech. Eng. Part D J. Automob. Eng. 2015, 229, 1494-1513. [CrossRef]

8. Nandakumar, C.S.; Subramanian, S.C. Design and analysis of a parallel hybrid electric vehicle for Indian conditions. In Proceedings of the IEEE International Transportation Electrification Conference (ITEC), Chennai, India, 27-29 August 2015.

9. Long, V.T.; Nhan, N.V. Bees algorithm based optimisation of component size and control strategy parameters for parallel hybrid electric vehicles. Int. J. Automot. Technol. 2012, 13, 1177-1183. [CrossRef] 
10. Keith, B.W.; Mathew, R.C. Using an Advanced Vehicle Simulator (ADVISOR) to Guide Hybrid Vehicle Propulsion System Development; National Renewable Energy Laboratory: Golden, CO, USA, 2014.

11. Tousif, A. Hybrid Electric Vehicles: The Next Big Thing in Fuel Crisis and Reduced Pollution; MECH 6340, Energy Management I Term Project Report; Dalhousie University: Halifax, NS, Canada, 2015.

12. Namwook, K.; Sukwon, C.; Huei, P. Optimal Control of Hybrid Electric Vehicles Based on Pontryagin's Minimum Principle. Control Syst. Technol. IEEE Trans. 2011, 19, 1279-1287. [CrossRef]

13. Wu, J.; Zhang, C.H.; Cui, N.X. PSO Algorithm-Based Parameter Optimization for HEV Powertrain and Its Control Strategy. Int. J. Automot. Technol. 2008, 9, 53-69. [CrossRef]

14. Powell, M.J.D. A Fast Algorithm for Nonlinearly Constrained Optimization Calculations. In Numerical Analysis; Lecture Notes in Mathematics; Springer: Berlin/Heidelberg, Germany, 1978; Volume 630, pp. 144-157.

15. Neubauer, J.; Wood, E. Accounting for the Variation of Driver Aggression in the Simulation of Conventional and Advanced Vehicle. In Proceedings of the SAE World Congress and Exhibition, NREL/CP-5400-57503, Detroit, MI, USA, 16-18 April 2013.

16. Montazeri-Gh, M.; Poursamad, A. Application of Genetic Algorithm for Simultaneous Optimization of HEV Component Sizing and Control Strategy. Int. J. Altern. Propuls. 2006, 1, 63-78.

17. Wipke, K.B.; Cuddy, M.R.; Burch, S.D. ADVISOR 2.1: A User-Friendly Advanced Power Train Simulation Using a Combined Backward/Forward Approach. IEEE Trans. Veh. Technol. 1999, 48, 1751-1761. [CrossRef]

18. Shuo, Z.; Xiong, R. Adaptive energy management of a plug-in hybrid electric vehicle based on driving pattern recognition and dynamic programming. Appl. Energy 2015, 155, 68-78.

19. Long, V.T.; Packianather, M.S. Application of a Pheromone-Based Bees Algorithm as an Optimizer Within a Multidisciplinary Design Optimization System for Power train Component Sizing and Control Parameters for Hybrid E-Vehicles. Int. J. Transp. Eng. Technol. 2015, 1-9. [CrossRef]

20. Gowrishankar, T.; Nirmal, K.A. Improving The Performance of A Parallel Hybrid Electric Vehicle By Heuristic Control Method. J. Electr. Eng. 2018, 18, 236-247.

21. Barlow, T.J.; Latham, S.; McCrae, I.S.; Boulter, P.G. A Reference Book of Driving Cycles for Use in the Measurement of Road Vehicle Emissions; Published Project Report PPR354; TRL Limited: London, UK, 2009.

22. Rizzoni, G.; Pisu, P.; Calo, E. Control strategies for parallel hybrid electric vehicles. In Proceedings of the IFAC Symposium on Advanced Automotive Control, Sydney, Australia, 6-8 September 2004; Volume 37, pp. 495-500.

23. Mahdiyeh, E. Gradient Based Artificial Bee Colony Algorithm. Int. J. Ind. Electron. Electr. Eng. 2016, 4, 50-54.

24. Bufu, H.; Wang, Z.; Xu, Y. Multi-Objective Genetic Algorithm for Hybrid Electric Vehicle Parameter Optimization. In Proceedings of the International Conference on Intelligent Robots and Systems, Beijing, China, 9-15 October 2006.

25. Yuce, B.; Packianather, M.S.; Mastrocinque, E.; Pham, D.T.; Lambiase, A. Honey Bees Inspired Optimization Method: The Bees Algorithm. Insects 2013, 4, 646-662. [CrossRef] [PubMed]

26. Jinling, W.; Wen, L. Study of Control Strategy Parameters and Component Sizing in Hybrid Electric Vehicles Using Particle Swarm Optimization. In Proceedings of the EVS26 International Battery, Hybrid and Fuel Cell Electric Vehicle Symposium, Los Angeles, CA, USA, 6-9 May 2012.

27. Guopu, Z.; Kwong, S. Gbest-guided artificial bee colony algorithm for numerical function optimization. Appl. Math. Comput. 2010, 217, 3166-3173. [CrossRef]

28. Subramani, P.; Rajendran, G.B.; Sengupta, J.; Pérez de Prado, R.; Divakarachari, P.B. A Block Bi-Diagonalization-Based Pre-Coding for Indoor Multiple-Input-Multiple-Output-Visible Light Communication System. Energies 2020, 13, 3466. [CrossRef]

(C) 2020 by the authors. Licensee MDPI, Basel, Switzerland. This article is an open access article distributed under the terms and conditions of the Creative Commons Attribution (CC BY) license (http://creativecommons.org/licenses/by/4.0/). 